\title{
Efficient Callus Induction and Plantlets Regeneration in Durum Wheat Using Mature
}

Embryos

D.C. TINAK EKOM ${ }^{1,3}$, S.M. UdUPA ${ }^{2}$, F. GABOUN $^{1}$, M.N. BENCHEKROUN $^{3}$ M.M. ENNAJI $^{4}$ and D.

${ }^{1}$ Biotechnology Research Unit, Institut National de la Recherche Agronomique (INRA), B.P. 415, Avenue de la Victoire, Rabat, Morocco

${ }^{2}$ ICARDA-INRA Cooperative Research Project, International Center for Agricultural

Research in the Dry Areas (ICARDA), B.P. 6299, Rabat, Morocco.

${ }^{3}$ Laboratory of Health and Environment Biotechnologies, Faculté des Sciences et Techniques

Mohammedia, Université Hassan II Mohammedia-Casablanca, PO 146 Mohammedia 20650

Morocco

${ }^{4}$ Laboratory of Virology and Hygiene \& Microbiology, Faculté des Sciences et Techniques

Mohammedia, Université Hassan II Mohammedia-Casablanca, PO 146 Mohammedia 20650

Morocco

(Received 18 May 2012; accepted 15 August 2012;

Communicated by C. Lantos)

The use of mature embryos as explants to initiate cultures is a best alternative to save time and costs, especially for producing somatic embryos for genetic transformation of durum wheat. However, plantlets regeneration from cultures derived from matured embryos is usually low. In this study, we tested matured embryos as explants from eight Moroccan durum wheat varieties ('Irden', 'Marzak', 'Kyperounda', 'Isly' 'Amria', 'Karim', 'Marouane' and 'Tomouh') to define suitable culture media for obtaining high frequencies of somatic embryogenesis and in vitro plantlets regeneration. For this purpose, we tested five induction and maintenance media (M1 to M5) based on MS media (macro and oligo-elements) which differed with respect to concentrations of plant hormones (2,4-D and BA), vitamins, sucrose, maltose, L-asparagine, and solidifying agents. All tested media induced embryogenic callus for the varieties and regenerate plantlets. However, a significant effect of variety, medium and variety x medium interaction were observed for callus induction and regeneration. Average callus growth as measured by relative fresh weight growth rate (RFWGR) across different media was the highest for 'Amria' (7215.4\%) and the lowest for Tomouh' (2088.2\%). M1 (2 mg/L 2,4-D) and M5 (3 mg/L 2,4-D) media gave highest RFWGR (6892.1\% and 6332\% respectively) and M3 (1 $\mathrm{mg} / \mathrm{L}$ 2,4-D) was the lowest $(3708.8 \%)$, across different varieties. However, the embryogenic callus from M3 media regenerated the highest percentage of plantlet, upon transfer to regeneration medium, for most of the varieties. For the varieties 'Marouane', 'Kyperounda', 'Marzak', 'Karim', and 'Tomouh', the favorable medium was M3, whereas, for 'Isly', 'Irden' and 'Amria', both M2 (2.5 mg/L BA and $2.5 \mathrm{mg} / \mathrm{L} \mathrm{2,4-D)}$ and M3 were the favorable media for embryogenic callus induction. In this study, for the first time, favourable media for induction and regeneration from mature embryo of Moroccan durum wheat varieties were identified. These media will be used for callus induction and genetic transformation.

Keywords: culture media; durum wheat; mature embryos; plantlets regeneration; somatic embryogenesis.

*Corresponding author: Phone: + 212661164616 / +212 6601572 42; Fax: + 212537 7755 30; E-mail: iraqid@yahoo.fr 
Abbreviations: 2,4-D - 2,4 Dichlorophenoxyacetic acid; B5 media - Gamborg B5 medium; BA - 6-Benzylaminopurine; IAA - Indole-3-acetic acid; MS media - Murashige and Skoog medium; RFWGR - Relative fresh weight growth rate.

\section{Introduction}

Durum wheat (Triticum durum L.) is the most important cereal crop in the Mediterranean basin. In Morocco, durum wheat is grown over an area ranging from 1 to 1.2 million hectares annually, and ranks the third after bread wheat and barley, with respect to production (MAPM 2011). The country's wheat productivity has been affected by various biotic and abiotic stresses (Karrou 2003).

Conventional breeding approaches can be complemented by in vitro techniques for genetic improvement of wheat (Bhalla 2006). Genetic improvement of wheat in vitro depends mostly on the ability of the plant tissue to regenerate into whole plants (Ren et al. 2010). The efficient in vitro regeneration of durum wheat plants is a basic prerequisite for genetic improvement through genetic transformation (Takumi and Shimada 1997).

In vitro regeneration of wheat plants have been achieved via organogenesis as well as embryogenesis from different explants sources such as immature embryos (Ozias-Akins and Vasil 1982; Li et al. 1992), matured embryos (Mendoza and Kaeppler 2002; Ren et al. 2010), shoot tips (Viertel and Hess 1996), immature inflorescences (Ozias-Akins and Vasil 1982), immature leaves (Rajyalakshmi et al. 1991) anthers (Zhou et al. 1991) and isolated microspores (Mejza et al. 1993). These tissues vary in their ability to regenerate whole plants. Nevertheless, immature embryos were the most efficient tissue source to regenerate plants in vitro (Jones 2005). However, it is usually difficult to obtain immature embryos throughout the year, and the suitable stage for their culture is also strictly limited. The use of mature embryos from dry seeds has several advantages: mature embryos are easy to handle, available year round and in bulk quantities. For this purpose, mature embryos as a favourable explants source are explored broadly in wheat tissue culture. Though, the major hurdle with mature embryos as explants is their low frequency of plant regeneration (Ren et al. 2010). Although plant regeneration has been achieved previously from callus cultures derived from mature embryos of durum wheat (Neiverth et al. 2010), the regeneration efficiency were inconsistent and also depended on genotype and medium composition (He et al. 1988). Moreover, studies on in vitro plantlet regeneration in durum wheat using mature embryos as explants derived from Moroccan varieties are lacking.

The objective of this study was to define media suitable for callus induction and plant regeneration of Moroccan durum wheat varieties using mature embryos as explants. While doing so, we compare the effects of media, varieties and their interaction on callus induction and plant regeneration obtained from mature embryo as explants.

\section{Materials and Methods}

\section{Plant materials and explants preparation}

Field grown seeds (matured caryopses) of durum wheat cultivars 'Irden', 'Marzak', 'Kyperounda', 'Isly' 'Amria', 'Karim', 'Marouane' and 'Tomouh' (Abbad-Andaloussi and Chahbar 2005) were used as the source for mature embryo culture. The seeds were procured from Experimental Research Station of INRA at Marchouch, Rabat, Morocco.

The seeds were then surface-sterilized by washing in ethanol $70 \%(\mathrm{v} / \mathrm{v})$ for 3 minutes, followed by a bath of $2.4 \%$ sodium hypochlorite plus a drop of Tween 20 for 30 minutes with 
agitation. Thereafter, they were rinsed three times in sterile distilled water. The disinfected seeds were soaked in sterile distilled water overnight to facilitate the embryos excision.

Mature embryos were aseptically dissected away from the caryopses and the remaining endosperm and radical removed to prevent early germination. The embryos were placed in a Petri dish containing the induction medium based on M1 (Iraqi et al. 2005), M2 (Karim et al. 2005), M3 (Gadaleta et al. 2006), M4 (Pellegrineschi et al. 2002) and M5 (Przetakiewicz et al. 2003) (Table S1*). The embryos were incubated on the media in the dark at $25^{\circ} \mathrm{C}$ for five weeks and the callus diameter and weight were recorded respectively each week and at the end of callogenesis and their relative fresh weight growth rate (RFWGR) of callus were determined (Daud et al. 2012):

$\mathrm{RFWGR}=\left(\mathrm{FW}_{\mathrm{f}}-\mathrm{FW}_{\mathrm{i}}\right) / \mathrm{FW}_{\mathrm{i}} \mathrm{100}$, where $\mathrm{FW}_{\mathrm{f}}=$ final fresh weight and $\mathrm{FW}_{\mathrm{i}}=$ initial fresh weight.

\section{Plant regeneration}

After five weeks, embryogenic calli from each replication were transferred to the regeneration medium (Iraqi et al. 2005) and incubated in the light (16 h per day) and temperature of $25^{\circ} \mathrm{C}$. The regeneration rate was calculated eight weeks after transfer of the callus. Percentage of plants regeneration was calculated as follows: (the number of plantlets regenerated / the number of callus transferred to the regeneration medium) x 100.

\section{Experimental design and statistical analysis}

A randomized complete block design (RCBD) was used with 8 varieties and 5 media $(8 \times 5=40$ treatments). The treatments consisted of 6 replications of each medium for each variety, each replication with 8 mature embryos. For the analysis of diameter, weight and RFWGR of callus and percentage of plants regeneration, Analysis of Variance (ANOVA) was performed using the General Linear Model (GLM) procedure in SAS (SAS Institute 1985). Mean of treatments were compared using Duncan's Multiple Range test (Steel and Torrie 1980).

\section{Results}

\section{Callus initiation and growth}

Two main types of calluses were observed in the cultures: non-embryogenic calluses and embryogenic calluses (Fig. 1). Non-embryogenic calluses were characterized by cream to brownish color and a soft, loose, watery nature, whereas, embryogenic were more pale in color, smooth and compact (Fig. 1). Mixtures of embryogenic calluses surrounded by nonembryogenic calluses were observed in most of the explants.

Callus growth was influenced not only by variety and medium but also by variety $x$ medium interaction (Table S2). Of the eight varieties tested, 'Karim' (8.63 mm) showed the highest mean callus diameter after 5 weeks of incubation of the explants on different media, followed by 'Isly' $(8.36 \mathrm{~mm})$, Tomouh (8.06) and 'Amria' $(7.91 \mathrm{~mm})$, whereas 'Kyperounda' showed the lowest $(6.85 \mathrm{~mm}$; Table 1). Among the five media, callus from M1, M4 and M5 media showed greater mean diameters (more than $8 \mathrm{~mm}$ ), whereas, M3 medium showed the lowest (6.15 mm; Table 1). However, all the genotypes showed increasing callus growth upon culturing the explants on all the media, but at different levels. For example, in 'Isly', the rate of increase of callus diameter was proportional to incubation time and higher callus growth

*Further details about the Electronic Supplementary Material (ESM) can be found at the end of the article. 
Figure 1. Embryogenesis and plant regeneration from mature embryos of wheat: (a) Embryogenic callus, (b) Nonembryogenic callus and (c) Embryogenic callus surrounded by non- embryogenic callus formation after 5 weeks of culture. Non-embryogenic (NE) callus was characterized by cream to brownish color and a soft, loose, watery nature, whereas, embryogenic (E) was more pale in color, smooth, compact, and contained embryonic structures occurring either as independent or fused nodules. (d) Plantlet regeneration on the regeneration medium (Iraqi et al. 2005) after 8 weeks of transfer

Table 1. Mean of callus diameter and relative fresh weight growth rate of callus (RFWGR) of eight durum wheat varieties obtained on five induction and maintenance media after 5 weeks of culturing and their effect on plantlets regeneration (\%)

\begin{tabular}{lllll}
\hline & $\begin{array}{l}\text { Callus diameter } \\
(\mathrm{mm})\end{array}$ & $\begin{array}{l}\text { Callus weight } \\
(\mathrm{mg})\end{array}$ & RFWGR (\%) & $\begin{array}{l}\text { Plantlet } \\
\text { regeneration (\%) }\end{array}$ \\
\hline Variety & & & & \\
\hline Irden & $7.36 \mathrm{~d}$ & $833.71 \mathrm{~d}$ & $5087.4 \mathrm{~cd}$ & $26.31 \mathrm{c}$ \\
Marouane & $7.17 \mathrm{de}$ & $1051.71 \mathrm{ab}$ & $5890.5 \mathrm{bc}$ & $32.53 \mathrm{bc}$ \\
Kyperounda & $6.85^{\mathrm{e}}$ & $777.14 \mathrm{de}$ & $4769 \mathrm{~d}$ & $30.54 \mathrm{bc}$ \\
Isly & $8.36 \mathrm{ab}$ & $726.57^{\mathrm{e}}$ & $4605 . \mathrm{d} 1$ & $35.46 \mathrm{ab}$ \\
Marzak & $7.26 \mathrm{~d}$ & $969.49 \mathrm{c}$ & $6330.8 \mathrm{ab}$ & $31.67 \mathrm{bc}$ \\
Karim & $8.63 \mathrm{a}$ & $995.74 \mathrm{bc}$ & $6242.1 \mathrm{ab}$ & $39.47 \mathrm{a}$ \\
Amria & $7.91 \mathrm{c}$ & $1094 \mathrm{a}$ & $7215.4 \mathrm{a}$ & $26.28 \mathrm{c}$ \\
Tomouh & $8.06 \mathrm{bc}$ & $465.06 \mathrm{f}$ & $2088.2^{\mathrm{e}}$ & $35.24 \mathrm{ab}$ \\
CD & 0.33 & 76.88 & 1061 & 6.06 \\
\hline Medium & & & & $6892.10 \mathrm{a}$ \\
\hline M1 & $8.50 \mathrm{a}$ & $1121.82 \mathrm{a}$ & $34.27 \mathrm{~b}$
\end{tabular}




\begin{tabular}{lllll} 
M2 & $6.76 \mathrm{~b}$ & $665.83 \mathrm{~d}$ & $4169.30 \mathrm{c}$ & $30.82 \mathrm{~b}$ \\
M3 & $6.15 \mathrm{c}$ & $643.97 \mathrm{~d}$ & $3708.80 \mathrm{c}$ & $50.29 \mathrm{a}$ \\
M4 & $8.43 \mathrm{a}$ & $866.68 \mathrm{c}$ & $5290.60 \mathrm{~b}$ & $24.23 \mathrm{c}$ \\
M5 & $8.67 \mathrm{a}$ & $1022.60 \mathrm{~b}$ & $6332 \mathrm{a}$ & $21.34 \mathrm{c}$ \\
$\mathrm{CD}$ & 0.26 & 60.78 & 839.1 & 4.79 \\
\hline
\end{tabular}

CD (0.05) according to the Duncan's Multiple Range test; M1 to M5 are the induction and maintenance media used. For composition of media, please refer to Table S1.

rates were observed for M1 $(9.71 \mathrm{~mm})$ and M5 $(9.38 \mathrm{~mm})$ and lower growth rates were observed for M2 $(7.09 \mathrm{~mm})$ and M3 $(6.88 \mathrm{~mm})$. For 'Karim', the best growth as indicated by callus diameter came from media M4 $(10.23 \mathrm{~mm})$, and M5 $(10.64 \mathrm{~mm})$ and the lowest diameter from M3 $(6.21 \mathrm{~mm})$ medium. However, for the 'Irden' the response of M1, M2, M4 and M5 were similar with respect to callus diameter measured after 5 weeks of incubation of the explants.

Relative fresh weight growth rate (RFWGR) calculated after 5 weeks of incubation of the explants also differed significantly among varieties across media (Table 1); 'Amria' recorded the highest (7215.4\%), followed by 'Marzak' (6330.8\%) and 'Karim' (6242.1\%), whereas, 'Tomouh' was the lowest (2088.2\%). RFWGR calculated after 5 weeks of incubation of the explants also differed significantly among media across varieties (Table 1): M1 recorded the highest (6892.1\%) followed by M5 (6332\%), and M4 (5290.6\%), whereas, M3 was the lowest (3708.8\%).

Callus production was strongly influenced by the media and the variety used (Table S2). A significant $(p<0.001)$ interaction between variety and medium was observed (Table S2). RFWGR of callus calculated after 5 weeks of culture on different induction and maintenance media showed that the highest RFWGR was observed on M1 for varieties 'Irden' (8914\%), 'Marouane' (7249\%), 'Marzak' (8969\%) and 'Amria'(9792\%); and for the rest of varieties, M5 gave the highest RFWGR (Table S3). In all these varieties, except 'Irden', culturing on M3 medium resulted in lowest RFWGR of callus.

\section{Plantlets regeneration}

After 5 weeks, callus was transferred to the regeneration medium. After 8 weeks of the culturing, the plantlets regeneration (Fig. 1) was recorded (Table 1). The induction and maintenance media used for callus induction had a significant effect on plantlets regeneration ( $p<0.001)$. Even though M1 and M5 showed higher RFWGR for callus after 5 weeks of culture (Table 1), the plantlets regeneration rates were lower from those calluses, $34.27 \%$ and $21.34 \%$, respectively (Table 1). On the other hand, M3 medium which induced least amount of callus, regenerated the highest percentage of plantlet regeneration (50.29\%; Table 1), indicating M3 medium induces more embryogenic callus than other media.

\section{Discussion}


In this study, we explored five callus induction and maintenance media (referred here after as M1, M2, M3, M4 and M5; Table S1) for their effect on callus formation and plants regeneration from mature embryo explants of eight Moroccan durum wheat varieties ('Irden', 'Marouane', 'Kyperounda', 'Isly', 'Marzak', 'Karim', 'Amria' and 'Tomouh'; AbbadAndaloussi and Chahbar 2005). Such studies allowed us to determine the medium favourable for each variety, which will help us for the use of mature embryos as explants in in vitro plant regeneration and genetic transformation of durum wheat.

Our results clearly showed that callus production was strongly influenced by the medium, the variety and medium x variety (Table S2) and confirm many others studies which showed that callus induction was influenced by the medium components and the genotype (Gadaleta et al. 2006; Ayolié et al. 2007; Monostori et al. 2008; Ren et al. 2010); and the expression of the morphogenetic competence in vitro was a complex phenomenon and influenced by physiological and genetic factors (Ayolié et al. 2007). M1 medium yielded the highest RFWGR for the varieties 'Irden', 'Marouane', 'Marzak' and 'Amria', whereas M5 for the rest of the varieties (Table S3). In all these varieties, except 'Irden', culturing on M3 medium resulted in lowest RFWGR of callus. These results indicate that callus weight improved by increasing 2,4-D (auxin) to $2 \mathrm{mg} / \mathrm{L}$ (as in the case of M1) in agreement with the finding of Malik et al. (2003) with mature seeds of wheat in the subculture media ; or $3 \mathrm{mg} / \mathrm{L}$ (as in the case of M5), similar to the results obtained by Munazir et al. (2010) with mature seeds culture of wheat. The beneficial effect of 2 and $3 \mathrm{mg} / \mathrm{L}$ of 2,4-D on callus induction of wheat mature embryos was also found by Raziuddin et al. 2010. In contrast, Mendoza and Kaeppler (2002) showed in bread wheat cultivar 'Bobwhite' that callus weight tended to decrease when concentration of 2,4-D was increased.

Our finding showed that the induction and maintenance media used for callus induction had a significant effect on plantlets regeneration. Increasing concentrations of 2,4$\mathrm{D}$, from $1 \mathrm{mg} / \mathrm{L}$ to 2 to $3 \mathrm{mg} / \mathrm{L}$ in induction and maintenance media (as in case of $\mathrm{M} 1$ and M5) decreased the rate of plantlets produced. It has been shown previously that the increasing concentration of 2,4-D had a detrimental effect on callus (increased brownish and necrotic appearance of callus) derived from mature bread wheat embryo, resulted in poor plantlet regeneration (Mendoza and Kaeppler 2002; Neiverth et al. 2010). On the other hand, M3 medium which induced least amount of callus, regenerated the highest percentage of plantlet regeneration. Therefore, M3 medium promoted the higher production of embryogenic callus, followed by M1 and M2, and M4 and M5 were the least, which was directly related to the regeneration capacity, as previously reported by Filippov et al. (2006).

In addition, the presence of maltose as carbohydrate source in the M3 induction medium could have a beneficial effect in the conversion of embryos to plantlets. The replacement of sucrose by maltose promoted the somatic embryos and increased efficiency of conversion of embryos to plant. This result is in agreement with the works of Mendoza and Kaeppler (2002) which indicated that substitution of sucrose by maltose enhanced the regeneration ability of callus from embryos of wheat. Our results confirm also the works of Gadaleta et al. (2006) which showed that inclusion $40 \mathrm{~g} / \mathrm{L}$ of maltose as sole carbon source had resulted in germination of wheat embryos and developed into plants.

The concentration of solidifying agent is another key factor influencing somatic embryogenesis in tissue culture system. Plant cell cultures are conventionally grown on the surface of solidified media, not only to prevent submergence, but also to simplify the control of the water status of the regenerating tissue. The nature and concentration of the solidifying 
agent determines the ease with which water and nutrients can be accessed by the tissue (Gugsa and Kumlehn 2011). The results presented here clearly showed that $3.5 \mathrm{~g} / \mathrm{L}$ of phytagel in M3 medium had a significant effect on callus formation and plant regeneration compared to $2.5 \mathrm{~g} / \mathrm{L}$ used in the others media. Gugsa and Kumlehn (2011) also reported that the concentration of phytagel between $3 \mathrm{~g} / \mathrm{L}$ to $5 \mathrm{~g} / \mathrm{L}$ were suitable for shoot regeneration of cereals such as Eragrostis tef.

Regeneration of plantlet from mature embryos derived callus is also controlled by their genetic makeup (Yin et al. 2011; Bahman et al. 2012). In our study, the varieties 'Karim', 'Isly', and 'Tomouh' produced higher plantlets regeneration, whereas 'Irden' and 'Amria' produced significantly lower plantlets regeneration.. The other genotypes were in between. However, plantlets regeneration varied significantly depending on the varieties and the induction and maintenance media used. For the varieties 'Marouane', 'Kyperounda', 'Marzak', 'Karim', and 'Tomouh', the favorable medium was M3, whereas, for 'Isly', 'Irden' and 'Amria', both M2 and M3 were favorable (Table S3).

In this study, we identified for the first time, favourable media for induction and regeneration from mature embryo of Moroccan durum wheat varieties. These media will be used for embryogenic callus induction from mature embryos and for genetic transformation

\section{Acknowledgments}

DI and SMU are grateful to ICGEB, Italy for generous funding. SMU is grateful to the ICARDA/Morocco Collaborative Grants Program for the support.

\section{References}

Abbad-Andaloussi, F., Chahbar, A. 2005. Amélioration génétique du blé dur. In: INRA (eds), La création variétale à l'INRA, méthodologie, acquis et perspectives (Genetic improvement of durum wheat. In: INRA [eds], breeding at INRA, methodology, achievements and prospects). National Institute of Agricultural Research (INRA), Rabat, Maroc, pp. 7-56. (in French)

Ayolié, K., El Yacoubi, H., Rochdi, A. 2007. Influence du 2,4-D et de l'explant embryonnaire sur la callogenèse du blé dur (Influence of 2,4-D and embryonic explant on durum wheat callus). Bull. Soc. Pharm. Bordeaux 146:97-112. (in French)

Bahman, F.N., Omidi, M., Amiritokaldani, M. 2012. Callus induction and plant regeneration of wheat mature embryos under abscisic acid treatment. Int. J. of Agriculture and Crop Sci. 4:17-23.

Bhalla, P.L. 2006. Genetic engineering of wheat - current challenges and opportunities. Trends Biotechnol. 24:305-311.

Daud, M.K., Shafaqat, A., Variath, M.T., Zhu, S.J. 2012. Antioxidative enzymes status in upland cotton callus culture under osmotic stresses. International Conference on Computational Techniques and Artificial Intelligence (ICCTAI'2012) Penang, Malaysia. Available at http://psrcentre.org/images/extraimages/212160.pdf.

Filippov, M., Miroshnichenko, D., Vernikovskaya, D., Dolgov, S. 2006. The effect of auxins, time exposure to auxin and genotypes on somatic embryogenesis from mature embryos of wheat. Plant Cell Tiss. Org. 84:100192-100201.

Gadaleta, A., Giancaspro, A., Belchl, A., Blanco, A. 2006. Phosphomannose isomerase, pmi, as a selectable marker gene for durum wheat transformation. J. Cereal Sci. 43:31-37. 
Gamborg, O.L., Miller, R.A., Ojima, K. 1968. Nutrient requirements of suspension cultures of soybean root cells. Exp. Cell Res. 50:151-158.

Gugsa, L., Kumlehn, J. 2011. Somatic embryogenesis and massive shoot regeneration from immature embryo explants of Tef. Biotechnol. Res. Int. 2011:1-7.

He, D.G., Yang, Y.M., Scott, K.J. 1988. A comparison of scutellum callus and epiblast callus induction in wheat: the effect of genotype, embryo age and medium. Plant Sci. 57:225-233.

Iraqi, D., Hakam, N., Labhilili, M. 2005. Transformation génétique des embryons immatures du blé tendre (Triticum aestivum) et du blé dur (Triticum durum) (Genetic transformation of immature embryos of bread wheat (Triticum aestivum) and durum wheat (Triticum durum). Al Awamia Moroccan J. Agric. Res. 115:3-16. (in French)

Jones, H.D. 2005. Wheat transformation: current technology and applications to grain development and composition. J. Cereal Sci. 41:137-147.

Karim, R., Chlyah, H., Badoc, A., Douira, A. 2005. Obtention de pieds néoformés suite à l'induction de cals embryogènes d'embryons zygotiques de blés par le borate de sodium et un extrait de Fusarium graminearum (Obtaining neogenic foot following the induction of embryogenic callus of zygotic embryos of wheat by sodium borate and an extract of Fusarium graminearum). Bull. Soc. Pharm. Bordeaux 144:195-210. (in French)

Karrou, M. 2003. Conduite du blé au Maroc (Behavior of wheat in Morocco). National Institute of Agricultural Research (INRA Editions), Rabat, Maroc, pp.57. (in French)

Li, Z.Y., Xia, G.M., Chen, H.M. 1992. Somatic embryogenesis and plant regeneration from protoplasts isolated from embryogenic cell suspension of wheat (Triticum aestivum L.). Plant Cell Tiss. Org. 28:79-85.

Malik, S.I., Rashid, H., Yasmin, T., Minhas, N.M. 2003. Effect of 2,4-dichlorophenoxyacetic acid on callus induction from mature wheat (Triticum aestivum L.) seeds. Int. J. of Agriculture and Biol. 6:156-159.

MAPM. 2011. Situation de l'Agriculture Marocaine (Agriculture situation in Morocco). No. 9, Ministry of Agriculture and Fisheries, Rabat, Morocco, 204 pp. Available at http://www.agriculture.gov.ma/sites/default/files/SAM9-2011.pdf. (in French)

Mejza, S.J., Morgant, V., Di Bona, D.E., Wong, J.R. 1993. Plant regeneration from isolated microspores of Triticum aestivum. Plant Cell Rep. 12:149-153.

Mendoza, M.G., Kaeppler, H.F. 2002. Auxin and sugar effects on callus induction and plant regeneration frequencies from mature embryos of wheat (Triticum aestivum L.). In Vitro Cell. Dev-Pl. 38:39-45.

Monostori, T., Rozik, E., Bus, T.G., Tanacs, L. 2008. The use of field grown plant material in somatic tissue cultures of spring wheat genotypes. Cereal Res. Commun. 36:1135-1138.

Munazir, M., Qureshi, R., Ali, G.M., Rashid, U., Noor ,S., Mehmood, K., Ali, S., Arshad, A. 2010. Primary callus induction, somatic embryogenesis and regeneration studies in selected elite wheat varieties from Pakistan. Pak. J. Bot. 42:3957-3965.

Neiverth, A., Silva, J.B.D., Schuster, I., Santos, M.F.D., Vendruscolo, E.C.G. 2010. Regeneration of wheat plants from wheat (Triticum aestivum L. cv. CD104) mature embryos. Scientia Agraria 11:101-108.

Ozias-Akins, P., Vasil, I.K. 1982. Plant regeneration from cultured immature embryos and inflorescences of Triticum aestivum L. (wheat): evidence for somatic embryogenesis. Protoplasma 110:95-105. 
Pellegrineschi, A., Noguera, L.M., Skovmand, B., Brito, R.M., Velazquez, L., Salgado, M.M., Hernandez, R., Warburton, M., Hoisington, D. 2002. Identification of highly transformable wheat genotypes for mass production of fertile transgenic plants. Genome 45:421-430.

Przetakiewicz, A., Orczyk, W., Nadolska-Orczyk, A. 2003. The effect of auxin on plant regeneration of wheat, barley and triticale. Plant Cell Tiss. Org. 73:245-256.

Rajyalakshmi, K., Grover, A., Maheshwari, N., Tyagi, A.K., Maheshwari, S.C. 1991. High frequency regeneration of plantlets from the leaf-bases via somatic embryogenesis and comparison of polypeptide profiles from morphogenic and non-morphogenic calli in wheat (Triticum aestivum). Physiol. Plantarum 82:617-623.

Raziuddin, J., Bakht Swati, Z.A., Shafi, M., Farhat, U., Akmal, M. 2010. Effect of cultivars and culture medium on callus formation and plant regeneration from mature embryos of wheat (Triticum aestivum L.). Pak. J. Bot. 42:639-652.

Ren, J.P., Wang, X.G., Yin, J. 2010. Dicamba and sugar effects on callus induction and plant regeneration from mature embryo culture of wheat. Agri. Sci. in China 9:31-37.

SAS Institute. 1985. SAS/STAT guide for personal computers, Version 6 edition. Cary, N.C: SAS Institute, USA, $378 \mathrm{pp}$.

Steel, R.G.D., Torrie, J.H. 1980. Principles and procedures of statistics: a biometrical approach, 2nd edition. McGraw-Hill, New York, USA. 633 pp.

Takumi, S., Shimada, T. 1997. Variation in transformation frequencies among six common wheat cultivars through particle bombardment of scutellar tissues. Genes Genet. Syst. 72:63-69.

Viertel, K., Hess, D. 1996. Shoot tips of wheat as an alternative source for regenerable embryogenic callus cultures. Plant Cell Tiss. Org. 44:183-188.

Yin, G.X., Wang, Y.L., She, M.Y., Du, L.P., Xu, H.J., Ma, J.X., Ye, X.G. 2011. Establishment of a highly efficient regeneration system for the mature embryo culture of wheat. Agr. Sci. in China 10:9-17.

Zhou, H., Zheng, Y., Konzak, C.F. 1991. Osmotic potential of media affecting green plant percentage in wheat anther culture. Plant Cell Rep. 10:63-66.

\section{Electronic Supplementary Material (ESM)}

Electronic Supplementary Material (ESM) associated with this article can be found at the website of CRC at http://www.akademiai.com/content/120427/

\section{Electronic Supplementary Table S1. Media composition}

Electronic Supplementary Table S2. Analysis of variance for effects of variety, medium and their interaction on callus diameter, callus weight and relative fresh weight growth rate

(RFWGR) of callus and on plantlets regeneration (\%) in durum wheat

Electronic Supplementary Table S3. Effect of medium and variety on relative fresh weight growth rate of callus (RFWGR) and plantlets regeneration in durum wheat 
In vitro Plantlet Regeneration in Durum Wheat 